\title{
Weathering product-harm crises
}

\author{
Kathleen Cleeren • Marnik G. Dekimpe • \\ Kristiaan Helsen
}

Received: 9 October 2006 / Accepted: 30 March 2007 /Published online: 26 April 2007

(C) Academy of Marketing Science 2007

\begin{abstract}
To counter the negative effects of a product-harm crisis, brands hope to capitalize on their equity, and often use advertising as a communication device to regain customers' lost trust. We study how consumer characteristics and advertising influence consumers' first-purchase decisions for two affected brands of peanut butter following a severe Australian product-harm crisis. Both pre-crisis loyalty and familiarity are found to form an important buffer against the product-harm crisis, although this resilience decreases over time. Also heavy users tend to purchase the affected brands sooner, unless their usage rate decreased significantly during the crisis. Brand advertising was found to be effective for the stronger brand, but not for the weaker brand.
\end{abstract}

K. Cleeren $(\bowtie)$

Faculty of Economics and Business Administration, Department of Marketing,

Maastricht University, P.O. Box 616,

6200 MD Maastricht, The Netherlands

e-mail: k.cleeren@mw.unimaas.nl

\section{G. Dekimpe}

Faculty of Economics and Business Administration,

Department of Marketing,

Tilburg University, P.O. Box 90153,

5000 LE Tilburg, The Netherlands

e-mail: m.g.dekimpe@uvt.nl

M. G. Dekimpe

Faculty of Economics and Applied Economics,

Catholic University Leuven,

Naamsestraat 69, 3000 Leuven, Belgium

K. Helsen

School of Business and Management, Department of Marketing,

Hong Kong University of Science and Technology,

Clear Water Bay, Hong Kong, China

e-mail: mkhel@ust.hk
Keywords Product-harm crises · Brand equity . Advertising $\cdot$ Multiple-event hazard model

\section{Introduction}

Product-harm crises are prevalent in the marketplace. Notable examples include traces of benzene in Perrier, the negative publicity affecting Vioxx following a report suggesting that its prolonged use would increase the chance of heart attacks, and Bausch \& Lomb's Renu contact lens cleaner increasing the risk of a fungal infection. In the foodservice industry, the Taco Bell chain has recently been confronted with an E. coli outbreak linked to its lettuce, and with pictures of a rat plague in one of its New York subsidiaries. ${ }^{1}$ Such crises can be devastating to a company and harmful for society. According to the U.S. Consumer Product Safety Commission (2005), injuries, deaths, and property damages related to crises cost over $\$ 700$ billion annually. Obviously, the financial losses for the firm involved tend to be huge as well. Apart from the enormous costs directly linked to a product recall, the out-of-stock situation and negative publicity may cause substantial revenue losses. Estimates for the direct costs of Perrier's 1990 crisis, for example, are around \$30 million (Berman 1999), while 1 year later sales had only reached $60 \%$ of their pre-recall level (Hartley 1995). Likewise, the Snow

\footnotetext{
${ }^{1}$ More information on these crises can be found on http://www.abc. net.au/4corners/content/2005/s1341036.htm, http://www.consumeraffairs. com/news04/2006/04/renu_withdrawal.html, http://money.cnn.com/ 2007/02/23/news/companies/taco_bell/index.htm, and http://money. cnn.com/2006/12/13/news/tacobell_lettuce/index.htm?postversion= 2006121322 for, respectively, the Vioxx case, the Bausch \& Lomb recall, the Taco Bell rat-plague incident, and the E.coli outbreak.
} 
Brand Milk food-poisoning scandal in Japan had a devastating impact on the company's bottom line: it incurred a loss of 51.6 billion yen in fiscal 2001, compared to a net profit of 3.3 billion yen in fiscal 1999 (Finkelstein 2005). Due to the increasing complexity of products, more stringent product-safety legislation, and more demanding customers, product-harm crises tend to occur ever more frequently (Dawar and Pillutla 2000). ${ }^{2}$

Previous research on product crises has often focused on providing checklists, advising on the role of different business functions during and after a product crisis (e.g., Berman 1999). Another research stream has concentrated on estimating the effect of the crisis on aggregate performance measures, such as stock prices (e.g., Davidson and Worrell 1992) and brand sales (e.g., van Heerde et al. 2007). While this research provides valuable insights, it does not examine individual differences in how consumers react to the crisis.

Individual differences have been looked at in lab experiments examining the impact of hypothetical brand crises on brand evaluations and purchase intentions. In these studies, the impact of negative news is found to be moderated by certain consumer characteristics, such as commitment to the brand (Ahluwalia et al. 2000), perceived severity of the crisis (Laufer et al. 2005), and brand familiarity (Ahluwalia 2002). As this research is mainly experimental in nature, a number of external-validity issues can be raised. ${ }^{3}$ First, the experimental setting might attract artificial attention to the crisis, and create a demand bias when subjects attempt to speculate on the purpose of the experiment (Shimp et al. 1991). Furthermore, reported intentions and behavior are known to not always coincide. In addition, these studies offer limited insight into the moderating effect of marketing decision variables such as advertising, an instrument companies often use to restore their brands' tarnished image. Finally, marketplace dynamics, such as spontaneous information sharing among consumers and competitive activity, are typically not accounted for (Dawar and Pillutla 2000).

In this study, we use scanner data from a natural experiment, and shed light on the impact of own and competitive advertising, while accounting for individuallevel differences in how consumers react to the crisis. We hereby respond to Winer's (1999) call for more scanner studies supporting results found in lab studies to enhance the

\footnotetext{
${ }^{2}$ The U.S. Consumer Product Safety Commission (2005), for example, completed 397 cooperative recalls in 2005, involving 67 million product units, compared to only 221 recalls affecting eight million product units in 1988 (Berman 1999). Of course, also the administration in power can impact the number of recalls.

${ }^{3}$ In another attempt to increase the external validity of experimental findings, Dawar and Pillutla (2000) used survey data on the awareness and the impact on brand equity of an ongoing real-life product-harm crisis.
}

latter's external validity. Indeed, this method triangulation provides greater confidence in the robustness of lab results if they are proven to also hold in "less clean" real-life settings.

Specifically, we use real-life household-scanner data that record consumer purchases, before, during and after a wellpublicized product-harm crisis. In June 1996, Kraft Foods, Australia's largest peanut-butter manufacturer, recalled its two peanut-butter products, Eta and Kraft, because they were linked to more than 100 cases of salmonella poisoning (Sydney Morning Herald 1996a). The bacterial infection was traced to a batch of contaminated peanuts, supplied to the group by an outside manufacturer. Kraft Foods Australia was engulfed in the worst crisis in its 70-year history, and remained off the shelves for almost 5 months during which the market shares of Eta and Kraft dropped from, respectively, 13 and $42 \%$ to zero. In the meantime, its main competitor Sanitarium took advantage of the crisis situation by stressing in several advertising campaigns that it had been roasting its own peanuts. Sanitarium's market share increased from 15 to $70 \%$ during the crisis period. Despite this spectacular performance boost for Sanitarium, overall demand for peanut-butter products was down by 30\% (Sydney Morning Herald 1996a, b). This crisis was also investigated in a recent study by van Heerde et al. (2007). However, their use of aggregate performance measures precluded the detection of any individual-level differences.

Within this setting, we focus on the first-purchase decision after the product-harm crisis, as it is typically associated with higher risk in the diffusion literature. Especially in case of a product-harm crisis, buying an affected brand is perceived as highly risky (Pennings et al. 2002), making the trial purchase a first hurdle to be taken in order to regain a consumer's trust. We study the effect of various consumer characteristics on the timing of the trial purchase of the affected brands after the crisis. In addition, we focus on the effectiveness of Kraft Foods' post-crisis advertising campaign, as well as the impact of advertising expenditures by non-affected competitors.

\section{Conceptual framework}

Product-harm crises can seriously hurt a firm's performance. During the prolonged out-of-stock situation often associated with the product recall, customers may switch to competing brands, or even decide to quit buying the category. Moreover, the company is likely to face a damaged image and a substantial drop in consumer trust (Dawar and Pillutla 2000). Apart from the apparent impact on the affected brands/companies, a product-harm crisis may also corrode trust in the product category as a whole, as the inadequacy of the production process can be perceived to be an industry-wide problem (De Alessi and Staaf 1994). 
The bad publicity surrounding the crisis tends to be weighed heavily when making product judgments-a phenomenon referred to as negativity bias - as it is perceived both as diagnostic and surprising (Herr et al. 1991). In addition, negative news is reported more frequently and more vividly, as it is against the norm (Weinberger and Lepkowska-White 2000), and considered more credible than positive news spread by the company itself (Ahluwalia et al. 2000). However, negativity effects can be moderated by several consumer characteristics. In addition, advertising may be used to counter the negative news, and be instrumental to re-establish trust in the category and brand.

Pre-crisis brand loyalty Loyal consumers are more likely to engage in biased processing (Ahluwalia et al. 2000). They tend to resist or discount information that is disconfirmatory or counterattitudinal, and to counter-argue negative news about their preferred brands more often to minimize cognitive dissonance (Dawar and Pillutla 2000). As a consequence, loyal consumers have been found to show more sympathy for the brand, and believe the company deserves their help (Stockmeyer 1996). Loyal customers have also been found to be less likely to switch brands during out-of-stock situations: because of their limited experience with competing items, their search costs tend to be higher. They also incur higher substitution costs when buying non-preferred items (Campo et al. 2000). We therefore expect a positive impact of consumers' pre-crisis loyalty on their post-crisis trial rate.

\section{Interaction between pre-crisis brand loyalty and time The} presence of a loyal customer base is a key indicator of brand equity (Aaker 1996, p. 319), which may offer resilience in the face of misfortune (Hoeffler and Keller 2003). Because of the product recall, people no longer have the opportunity to increase their personal experience with the affected brand, while companies are not inclined to advertise a product that is not available (van Heerde et al. 2007). As personal experience and advertising are instrumental in maintaining brand equity (Aaker and Biel 1993), the protection offered by the pre-crisis loyalty of the customer base is expected to erode over time.

Pre-crisis brand familiarity People exposed to new information on a familiar brand perceive positive news to be as diagnostic as negative information, as opposed to unfamiliar customers who tend to weigh negative news more heavily (Ahluwalia 2002). Jolly and Mowen (1985) found that news of a product recall influenced evaluations of a company more negatively when the company was unknown. Furthermore, familiarity increases a consumer's confidence toward the brand (Laroche et al. 1996), and familiar brands are often perceived to be less responsible for a crisis (Mowen 1980). As such, we expect a higher repurchase rate after the crisis for customers familiar with the affected products. ${ }^{4}$ However, pre-crisis brand familiarity could also be a liability. Brands familiar to a large fraction of the population are likely to receive more scrutiny from the media than less familiar ones (Rhee and Haunschild 2006), making their crisis more salient to more customers.

Pre-crisis category usage Heavy users are likely to be more appreciative of the benefits of the product (Lim et al. 2005), making them less likely to fully defect from the category. Given their extensive experience with the category, they are also in a better position to make product judgments, and are expected to have lower perceived risks (Goering 1985). We therefore expect a positive impact of pre-crisis category usage on post-crisis trial rates.

Change in category usage As indicated earlier, a productharm crisis may influence consumption in the category as a whole (De Alessi and Staaf 1994). Consumers who do not reduce category consumption, however, seem to have sustained trust in the category. It should be easier to convince them to try the affected products once they become available again. Indeed, a first hurdle (i.e., buying in the category) has already been taken. On the other hand, as category consumption during the crisis can only occur through the purchase of competing (non-affected) brands, these customers' familiarity and behavioral loyalty will increasingly shift towards those brands, making it harder to convince them to switch back to the affected products. Because of these countervailing forces, we do not advance a directional hypothesis.

Cross and competitive purchases Apart from consumption during the crisis, also the usage of the category after the crisis is important. We distinguish between after-crisis consumption of the non-affected brands (labeled as competitive purchases) and of the other affected brand (referred to as cross purchases). If consumers buy another brand after the crisis, the resulting purchase-feedback effects (Goldfarb 2006) may adversely impact the likelihood of trial of the affected brand under investigation. On the other hand, it may also be argued that consumers purchasing other brands after the crisis have not lost trust in the category as a whole, and by consequence are easier to convince to repurchase the affected brands. Again, no directional hypothesis is given because of the two aforementioned opposing forces.

Own advertising The size of advertising effects tends to be fairly small for established brands (Lodish et al. 1995). One would expect the effectiveness of post-crisis investments to

\footnotetext{
${ }^{4}$ We do not consider an interaction effect with time, as our operationalization of pre-crisis brand familiarity already accounts for a decreasing impact with time.
} 
be even smaller, as the crisis may have damaged the brand's reputation. On the other hand, it has been argued that the heightened brand awareness and media attention during a crisis period could actually result in a higher return on advertising investments than if they were part of routine equity-building activities (Dawar 1998).

Cross and competitive advertising Apart from own advertising, two kinds of "competing" advertising may have an impact: by other affected brands (which we label as cross advertising) and by non-affected competitors (referred to as competitive advertising). Their impact on the trial rate of an affected brand may be two-fold. On the one hand, this advertising could primarily serve an informational role, trying to resolve some of the uncertainty and risks associated with buying any product in the affected category (Byzalov and Shachar 2004). Because of the resulting primary-demand effect, also the trial rate of directly affected products could be influenced positively. On the other hand, cross and competitive advertising can primarily have a persuasive role, emphasizing the differential advantages of the specific brand being advertised, thereby delaying the purchase of all other brands. It remains an empirical question to establish which effect prevails.

\section{Model}

We focus on when consumers start to purchase the affected brands again after a product crisis. Hazard models are often used to study timing decisions because of two key advantages. First, they can easily accommodate that the actual purchase timing is unknown for households who have not yet bought the brand before the end of the observation period (referred to as censored observations). If the number of censored households were small, one might consider excluding them from the analysis. However, $80 \%$ (51) of the households in our sample did not yet purchase Eta (Kraft) by the end of the observation period. Omitting them from the sample would involve a considerable loss of information, and may result in biased parameter estimates. Alternatively, one could consider assigning each of these observations the observed length until the end of the observation period. However, this would underestimate these households' true timing, and again result in a substantial bias (Allison 1984).

Second, when relating a timing decision to covariates, one often encounters the difficulty that this timing depends on the entire time path of values for these covariates, rather than on a single value. For example, the trial decision may depend on whether and when competing products were bought in the preceding weeks. Unlike conventional regression analyses, hazard models are well suited to deal both with censored observations and with time-varying covariates (see Allison 1984 for an in-depth discussion).
Following earlier studies in marketing (e.g. Mitra and Golder 2002), we specify a semi-parametric proportional hazard model (Cox 1972) for Eta:

$\lambda_{\mathrm{Eta}, i}(t)=\lambda_{0, \mathrm{Eta}}(t) \exp \left[\beta_{\mathrm{Eta}} X_{\mathrm{Eta}, i}(t)\right] \exp \left[\alpha_{\mathrm{Eta}} Z_{\mathrm{Eta}, i}(t)\left(t+t^{c}\right)\right]$

$\lambda_{0, \mathrm{Eta}}(t)$ is the baseline hazard, which corresponds to the trial rate of the base group, i.e. households for which all covariates are zero, and $X_{\mathrm{Eta}, i}(t)$ is a vector of covariates (including precrisis brand loyalty, pre-crisis familiarity and category usage, change in category usage, own advertising, cross advertising, competitive advertising, cross purchases and competitive purchases) for consumer $i$ that cause an up- or downward adjustment in that baseline. In the final term, we interact the covariates in the $Z_{\mathrm{Eta}, i}(t)$ vector with the time elapsed since the start of the crisis $\left(t+t^{\mathrm{c}}\right)$ to capture the covariates for which the effect is allowed to gradually increase/decrease over time. ${ }^{5}$ In our model $Z_{\mathrm{Eta}, i}(t)$ consists of pre-crisis brand loyalty.

A similar hazard model is specified for Kraft. We refer to the Appendix for a discussion on the partial likelihood method used to estimate the parameters from this multipleevent hazard model.

\section{Data}

Household scanner data describing the peanut-butter purchases of 615 households in two major Australian cities (Melbourne and Sydney) were obtained from ACNielsen Australia. The data covered 5 years (1996-2000). These were split in two initialization periods and one estimation period. The former cover the period from $01 / 01 / 1996$ to $06 / 26 / 1996$ (the date the brands were recalled), and from 06/27/1996 until $11 / 24 / 1996$ (the moment the brands were available again). We use them to quantify consumer purchase characteristics before and during the crisis, respectively. The estimation period goes from 11/25/1996 to 12/31/2000. All households made at least one peanut-butter purchase in the pre-crisis period, and are observed throughout both initialization periods. One hundred twenty-three $(20 \%)$ made a postcrisis purchase of Eta, while 299 (49\%) bought Kraft again. ${ }^{6}$ The median (completed) time to repurchase Eta after the crisis is 341 days, as opposed to only 196 days for

\footnotetext{
${ }^{5}$ This time component consists of the length of the recall period $\left(t^{\mathrm{c}}\right)$ and the time elapsed since the product is available again $(t)$.

${ }^{6}$ This sample size is in line with earlier applications of hazard-rate models in the marketing literature (see e.g. Gielens and Dekimpe 2007, Helsen and Schmittlein 1993 or Mitra and Golder 2002). Also the number of completed observations (both in absolute and relative terms) is comparable to the number observed in earlier studies. Moreover, even if one would make complete abstraction of the information content contained in the censored observations, our parameter to observation ratio would still exceed considerably the 1:5 ratio advocated in Leeflang et al. (2000).
} 
Table 1 Descriptive statistics for explanatory variables

\begin{tabular}{|c|c|c|c|c|}
\hline Variable & Mean & Standard deviation & Minimum & Maximum \\
\hline \multicolumn{5}{|l|}{ Pre-crisis brand loyalty } \\
\hline Eta & 13 & 31 & 0 & 100 \\
\hline Kraft & 42 & 46 & 0 & 100 \\
\hline \multicolumn{5}{|l|}{ Pre-crisis brand familiarity } \\
\hline Eta & 159 & 45 & 3 & 178 \\
\hline Kraft & 119 & 67 & 1 & 178 \\
\hline \multicolumn{5}{|l|}{ Category usage } \\
\hline Pre-crisis category usage (in grams per day) & 6.83 & 6.58 & 1.12 & 56.88 \\
\hline Change in category usage (in percentage) & $-15 \%$ & $108 \%$ & $-100 \%$ & $1,130 \%$ \\
\hline \multicolumn{5}{|l|}{ Cross purchases (in $100 \mathrm{~g}$ ) } \\
\hline Eta & 9.57 & 23.04 & 0.00 & 252.50 \\
\hline Kraft & 1.63 & 6.24 & 0.00 & 93.60 \\
\hline \multicolumn{5}{|l|}{ Competitive purchases (in $100 \mathrm{~g}$ ) } \\
\hline Eta & 17.42 & 49.73 & 0.00 & 798.75 \\
\hline Kraft & 21.83 & 52.26 & 0.00 & 667.5 \\
\hline \multicolumn{5}{|l|}{ Advertising $(1,000,000 \text { AU } \$)^{\mathrm{a}}$} \\
\hline Eta advertising & 1.95 & 3.20 & 0.00 & 13.73 \\
\hline Kraft advertising & 11.58 & 8.11 & 0.42 & 46.17 \\
\hline Competitive advertising & 2.46 & 5.93 & 0.00 & 35.26 \\
\hline Area $^{\mathrm{b}}$ & $52 \%$ & & & \\
\hline Household size & 3.43 & 1.46 & 1.00 & 8.00 \\
\hline \multicolumn{5}{|l|}{ Inventory (in $100 \mathrm{~g}$ ) } \\
\hline Eta & 3.27 & 2.30 & 0.00 & 27.50 \\
\hline Kraft & 2.85 & 2.40 & 0.00 & 26.25 \\
\hline
\end{tabular}

${ }^{\text {a }}$ To illustrate the variation over the analyzed 214-week period of the time-varying advertising measures, we report the mean and standard deviation of the adstock variables over the estimation period.

${ }^{\mathrm{b}}$ Dummy variable indicating whether the household lives in Sydney (value 1) or Melbourne (value 0). We report the proportion of households having the value 1 .

Kraft. Weekly advertising spending (in AU\$) by the major brands was also provided by AC Nielsen Australia.

We now turn to the operationalization of the explanatory variables. Given that we use scanner data, our measures are behavioral rather than attitudinal. Similarly, we focus on purchase history instead of consumption history (see Bucklin et al. 1998 for a similar practice). Table 1 shows key descriptive statistics. In line with Bucklin et al. (1998), we specify pre-crisis loyalty to an affected brand as its within-household market share before the crisis (Pre-crisis brand loyalty). As argued by Aaker (1996, p. 332), precrisis market share offers a good summary measure of the brand's equity before the crisis. We operationalize pre-crisis brand familiarity as the number of days since the last purchase before the start of the crisis (Pre-crisis brand familiarity). ${ }^{7}$ In contrast to a simpler $0 / 1$ operationalization, this measure takes into account the decreasing impact over

\footnotetext{
${ }^{7}$ Households that did not purchase the affected brand before the crisis were given the maximum value for pre-crisis familiarity (178 days). In unreported analyses, we increased this upper value by $10 \%$. Our substantive results were not affected.
}

time of a previous purchase experience with the brand (Mehta et al. 2004). Familiarity is closely linked with brand awareness, another pillar of brand equity (Aaker 1991, p. 19, 64). As in Bucklin et al. (1998), we measure category usage as the average daily purchase quantity. We consider both average category consumption before the crisis (Pre-crisis category usage), and the difference (in percentage terms) between average category usage during and before the crisis (Change in category usage). Cross and Competitive Purchases are specified as two weekly time-varying variables measuring the total volume purchased by the household of, respectively, the other affected brand and the non-affected competitors since the end of the crisis. With regard to advertising, we include three weekly time-varying covariates measuring advertising of, respectively, the affected brand ( $O w n$ Advertising), the other affected brand (Cross Advertising), and the non-affected competitors (Competitive Advertising). To also capture potential carry-over effects of advertising, we estimate the stock of advertising effort available to the brand as an exponentially weighted average of current and past advertising expenditures, for which the decay parameter is determined through a grid search (see Tellis and Weiss 1995 
Table 2 Empirical results

\begin{tabular}{|c|c|c|c|}
\hline & Hypothesized effect & Eta & Kraft \\
\hline Pre-crisis brand loyalty & + & $0.015^{\mathrm{c}}(0.005)$ & $0.017^{\mathrm{c}}(0.004)$ \\
\hline Interaction between pre-crisis brand loyalty and time & - & $-1.7 \mathrm{e}-05^{\mathrm{c}}(7.6 \mathrm{e}-06)$ & $-1.8 \mathrm{e}-05^{\mathrm{c}}(7.5 \mathrm{e}-06)$ \\
\hline Pre-crisis brand familiarity & $+/-$ & $-0.007^{\mathrm{c}}(0.002)$ & $-0.003^{\mathrm{b}}(0.001)$ \\
\hline Pre-crisis category usage & + & $0.022^{\mathrm{b}}(0.012)$ & $0.027^{\mathrm{b}}(0.014)$ \\
\hline Change in category usage & $+1-$ & $0.050(0.108)$ & $0.107^{\mathrm{b}}(0.052)$ \\
\hline Cross purchases & $+/-$ & $-0.018^{\mathrm{b}}(0.008)$ & $0.011(0.012)$ \\
\hline Competitive purchases & $+/-$ & $-0.001(0.002)$ & $-0.003(0.005)$ \\
\hline Own advertising & + & $-0.261(0.178)$ & $0.107^{\mathrm{b}}(0.055)$ \\
\hline Cross advertising & $+/-$ & $0.009(0.088)$ & $0.164(0.129)$ \\
\hline Competitive advertising & $+/-$ & $-0.090^{\mathrm{a}}(0.051)$ & $-0.063^{\mathrm{b}}(0.028)$ \\
\hline \multicolumn{4}{|l|}{ Control variables } \\
\hline Area & $+/-$ & $0.239(0.470)$ & $-0.210(0.349)$ \\
\hline Household size & + & $0.099^{\mathrm{a}}(0.066)$ & $0.078^{\mathrm{b}}(0.044)$ \\
\hline Inventory & - & $0.013(0.039)$ & $-0.090^{\mathrm{c}}(0.032)$ \\
\hline
\end{tabular}

Robust standard errors between brackets. ${ }^{\mathrm{a}},{ }^{\mathrm{b}}$ and ${ }^{\mathrm{c}}$ indicate a significant result at, respectively, the 10,5 and $1 \%$ significance level. Reported significance tests are one-sided in case a directional hypothesis is specified, and two-sided otherwise.

for a similar practice). ${ }^{8}$ As control variables, we also add the area of residence (Melbourne or Sydney), the household size, as well as the volume purchased in the category on the previous purchase occasion. The latter variable controls for potential inventory effects.

\section{Results}

Table 2 shows the parameter estimates for the model outlined before. Pre-crisis loyalty has a significant $(p<$ $0.01)$ positive impact on trial for both Eta and Kraft. This supports earlier experimental findings that loyal customers are less sensitive to negative news (Ahluwalia et al. 2000), and is in line with Campo et al. (2000) that loyal customers switch less in an out-of-stock situation due to higher substitution and search costs. This protection is found to gradually erode, however, as indicated by the negative interaction between loyalty and time $(p<0.01)$. The parameter estimates for pre-crisis brand familiarity are significantly negative $(p<0.01$ and $p<0.05$ for Eta and Kraft, respectively). ${ }^{9}$ This finding confirms that product

\footnotetext{
$\overline{{ }^{8} \text { The adstock variables are measured as } A D S T O C K_{t}=\alpha A D V_{t}+}$ $(1-\alpha) A D S T O C K_{t-1}$, where $A D V_{t}$ is the advertising expenditure in week $t$. $\alpha$ reflects the decay in advertising effectiveness. We allow for different decay parameters for advertising expenditures by the three brands (Eta, Kraft and non-affected competitors). The optimal values, obtained through a grid search, ranged from 0.1 (Eta) to 0.2 (nonaffected competitors). The initialization period for the adstock variables corresponds to the period before the reintroduction of the affected brands (11 months).

${ }^{9}$ Since the degree of pre-crisis familiarity decreases with the number of days since the last purchase before the crisis, a negative sign indicates that less familiarity delays trial.
}

experience can trigger defensive strategies against negative information on the brand (Ahluwalia et al. 2001), although this applies mostly for recent purchases because of forgetting (Mehta et al. 2004). The effect of pre-crisis category usage on the probability of trial is significantly positive $(p<0.05)$ for both Eta and Kraft. Heavy users are less inclined to cancel their purchases, as they are more familiar with the benefits of the product (Lim et al. 2005), and have lower perceived risks than light or medium users (Goering 1985). Apart from the category usage before the crisis, also the change in category usage during the crisis is important. A reduction is indicative of the extent to which trust in the category as a whole is lost. A positive effect (causing a delayed trial if the usage rate is reduced) is obtained for both brands, even though statistical significance is only obtained for Kraft $(p<0.05) .{ }^{10}$ In terms of the cross-purchase effects, an interesting asymmetry is observed. While a purchase for the stronger brand (Kraft) delays $(p<0.05)$ the subsequent trial of the smaller brand (Eta), no such effect is observed when Eta was first purchased. Strong brands are known to impact competitors extensively, while their vulnerability is typically low (Kamakura and Russell 1989). Competitive purchases did

\footnotetext{
${ }^{10}$ In unreported analyses, we also tested for an interaction effect between this category-change effect and the perceived substitutability between the brands in the category. The latter was proxied by a dummy indicating whether or not that consumer was a switcher before the crisis. Following Lim et al. (2005), this dummy takes the value of one if each brand's pre-crisis loyalty is less than or equal to $50 \%$. The interaction effect was significant and positive $(p<0.1)$ for both brands, while the main effect for Kraft remained. This indicates that the trust issue is important in general, but even more so for households with a high perceived substitutability of the brands in the category. We thank an anonymous reviewer for pointing this out.
} 
not $(p>0.10)$ delay the purchase of either brand. As such, the two opposing forces (i.e. a negative feedback and a positive trust effect) seem to result in a non-significant net effect. While own advertising has a significant positive effect on the trial probability of Kraft $(p<0.05)$, advertising expenditures for Eta are not effective in stimulating Eta's post-crisis trial rate $(p>0.10)$. Using aggregate analyses, and focusing on the total sales impact rather than trial, van Heerde et al. (2007) also obtained a non-significant own advertising effect for Eta, and a positive post-crisis advertising effectiveness for Kraft. Not surprisingly, as cross-effects tend to be smaller than own effects, Eta was not helped by Kraft's advertising either, while it also did not have enough clout to create a positive spill-over to Kraft. With regard to competitive advertising from nonaffected competitors, we find a negative effect for both Kraft $(p<0.05)$ and Eta $(p<0.10)$. This implies that competitors probably used their advertising more to persuade consumers to purchase the advertised brands than to re-establish trust in the category. In unreported analyses, we checked for interaction effects between these advertising variables and the aforementioned individual-level characteristics. No such evidence was found.

Finally, two of the control variables turned out to be significant. Inventory has the expected negative sign for Kraft, while the parameter estimate for household size is significantly positive for both brands, supporting the idea that larger households purchase more frequently. The place of residence had no significant effect on the trial probabilities.

\section{Discussion}

To overcome negative crisis effects, companies hope that their brand equity will help them weather the storm, and tend to resort to advertising communications to rebuild their tarnished image. Our research, though limited to one case study, allows us to contrast along both dimensions the performance of a 'strong' (Kraft) and 'weaker' (Eta) brand owned by the same company (Kraft Foods). Both brands were recalled for 5 months, during which their market shares dropped from 13 (Eta) and 42\% (Kraft) to zero. While Kraft was able to reach $70 \%$ of its pre-crisis sales level within one quarter of its reintroduction, Eta had a much harder time to recover, with less than half of its precrisis sales level recovered after one quarter. Our findings help put these differences in perspective.

First, we found that pre-crisis equity indeed provides an important protection against product-harm crises. Even after an out-of-stock situation of five months, both loyal and more familiar consumers (i.e. who bought the brand more recently) showed a significantly higher trial probability once the product was back on the shelves. Even though the parameter estimates were comparable for both brands, Kraft's pre-crisis loyalty ( $42 \%$ on average, see Table 1$)$ and familiarity (119 days) were considerably higher than for Eta (13\% and 159 days), giving the former more resilience against the crisis. If Kraft's pre-crisis loyalty had been only half as large (i.e. $21 \%$ rather than $42 \%$ ), its initial trial rate following its relaunch would have been $25 \%$ lower. Moreover, strong brands have been found to be less vulnerable and to have more clout. We find that these effects also apply to product crises: households who bought Kraft became less likely to also buy Eta, while the reverse did not hold. Hence, apart from the well-documented benefits (e.g., Aaker 1991) that accrue to the brand in prosperous times (such as an increased effectiveness of marketing programs, the possibility of premium pricing, and a higher success rate for brand extensions), we identify the creation of a buffer against negative events as another important reason to invest in brand equity. While this function has been mentioned in the brand-equity literature (e.g., Hoeffler and Keller 2003), our results offer empirical validation in a non-laboratory setting.

However, this protection does not extend indefinitely. During the recall period, consumers cannot nurture their relationship with the brand through personal experiences, while companies are not inclined to advertise a brand that is not available. As a consequence, the loyalty effect tends to decrease over time. This decrease is not negligible: after the 5-month recall period, already more than $15 \%$ of the initial loyalty protection was lost for both brands. In order to avoid this erosion, one should try to keep the recall period as short as possible, and perhaps announce well ahead of time the products' renewed availability.

Also the intensity of category usage was found to be an important moderator. Usage increases the experience with the category and decreases the perceived risks of using the product. However, not only pre-crisis category usage matters. A crisis can impact other-not directly affectedbrands, as the inadequacy of the production process may be perceived to be an industry-wide problem. Consumers who cancel all (or most) of their purchases during the recall period have lost trust in the category, and have switched to other categories. Bringing them back is hard, and may take a prolonged effort from all industry participants.

Finally, companies often resort to advertising to restore trust in their affected brands (Hale et al. 2005). Brand advertising for Kraft turned out to be effective in convincing consumers to return to the brand; however, Eta's advertising was not. Eta's management may have realized this, which may explain why so little was spent on Eta in the months following the crisis (as also observed in van Heerde et al. 2007). Even though more research is needed across other brands and product crises to replicate this observation, it suggests an additional benefit of having a strong equity: not only does it offer a direct buffer against 
product crises, it also increases the effectiveness of postrecall communication efforts. In combination with the considerable effort spent on advertising Kraft (as it was clearly out-spending its rivals, see Table 1), this may explain further Kraft's quick recovery.

Different avenues for future research can be formulated. First, one could examine whether a crisis also affects other components of purchase behavior such as quantity and category-consumption decisions. Rather than just focusing on the trial decision, one could also consider the subsequent purchases. Furthermore, we focused on the extent of advertising expenditure, while it may be important to also look at the content of the advertisements. Similarly, all our measures were behavioral. Even though loyalty has been called "a core dimension of brand equity ... of sufficient relevance to use as a criterion variable" (Aaker 1996, p. 319), other, more attitudinal measures of the brand equity construct would be useful to consider as well. Finally, we focused on one product-harm crisis. It would be useful to replicate our analysis to other crises. An obvious candidate (given that it also involves a salmonella poisoning linked to the consumption of peanut butter) is the recent US crisis affecting ConAgra's Peter Pan and Great Value brands (Longpre and Nolan 2007). However, to increase the variability in industry, crisis characteristics, and recovery strategy, it would be useful to also apply our approach to product crises in other categories/industries. Not only would such studies enable empirical generalizations, they could also give insight into the moderating impact of competitive response strategies (Dawar and Pillutla 2000), and provide more insights on the appropriate courses of action for brands of different strength.

Acknowledgement The authors thank Katrijn Gielens, Harald van Heerde, Frank Verboven and Luk Warlop, as well as the editor and four anonymous reviewers for valuable comments and suggestions. This research was funded by the HKUST Research Grants Council (no. 6148/02H) (Dekimpe and Helsen), and the Flemish Science Foundation (FWO) under grant nr. G.0116.04 (Dekimpe). The authors acknowledge the assistance of ACNielsen Australia in providing the datasets.

\section{Appendix A}

Estimation of the semi-parametric hazard model specified in Eq. 1 is done by maximizing the partial likelihood, which can be written as (see Allison 1984 for an in-depth discussion):

$L=\prod_{i=1}^{N}\left[\frac{\exp \left[\beta_{\mathrm{Eta}} X_{\mathrm{Eta}, i}\left(t_{i}\right)\right] \exp \left[\alpha_{\mathrm{Eta}} Z_{\mathrm{Eta}, i}\left(t_{i}\right)\left(t_{i}+t^{c}\right)\right]}{\sum_{j=1}^{N} r_{\mathrm{Eta}, i j} \exp \left[\beta_{\mathrm{Eta}} X_{\mathrm{Eta}, j}\left(t_{i}\right)\right] \exp \left[\alpha_{\mathrm{Eta}} Z_{\mathrm{Eta}, j}\left(t_{i}\right)\left(t_{i}+t^{c}\right)\right]}\right]^{d_{\mathrm{Ea}, i}}$

with $N$ the total number of households included. The dummy variable $d_{\text {Eta, } i}$ indicates whether the observation for consumer $i$ is completed $\left(d_{\mathrm{Eta}, i}=1\right)$ or not $\left(d_{\mathrm{Eta}, i}=0\right)$. It excludes from the numerator all right-censored households, i.e. those who did not purchase Eta during the observation period. For households who made a purchase at a specific time $t_{i}$, one considers the likelihood that the purchase was made by household $i$ rather than by any of the other households still "at risk" (i.e. who have not yet purchased the product at an earlier point in time). To determine the relevant risk set, a set of indicator variables $r_{\mathrm{Eta}, i j}$ is created, with $r_{\mathrm{Eta}, i j}=1$ if household $j$ has not yet bought Eta before $t_{i}$, and zero otherwise. Even though right-censored observations are excluded from the numerator in Eq. 2, they appear in the risk-set composition of the denominator. Note that the baseline hazard cancels out from the partial likelihood function. As a result, no distributional specification for the baseline hazard is needed.

As two brands, Eta and Kraft, were affected by the product-harm crisis under consideration, we extend the single-event model specified in Eq. 2 to a multiple-failure model, by considering both partial likelihoods:

$$
\begin{aligned}
& L=\prod_{i=1}^{N}\left[\frac{\exp \left[\beta_{\mathrm{Eta}} X_{\mathrm{Eta}, i}\left(t_{i}\right)\right] \exp \left[\alpha_{\mathrm{Eta}} Z_{\mathrm{Eta}, i}\left(t_{i}\right)\left(t_{i}+t^{c}\right)\right]}{\sum_{j=1}^{N} r_{\mathrm{Eta}, i j} \exp \left[\beta_{\mathrm{Eta}} X_{\mathrm{Eta}, j}\left(t_{i}\right)\right] \exp \left[\alpha_{\mathrm{Eta}} Z_{\mathrm{Eta}, j}\left(t_{i}\right)\left(t_{i}+t^{c}\right)\right]}\right]^{d_{\mathrm{Eta}, i}} \\
& \times \prod_{i=1}^{N}\left[\frac{\exp \left[\beta_{\mathrm{Kraft}} X_{\mathrm{Kraft}, i}\left(t_{i}\right)\right] \exp \left[\alpha_{\mathrm{Kraft}} Z_{\mathrm{Kraft}, i}\left(t_{i}\right)\left(t_{i}+t^{c}\right)\right]}{\sum_{j=1}^{N} r_{\mathrm{Kraft}, i j} \exp \left[\beta_{\mathrm{Kraft}} X_{\mathrm{Kraft}, j}\left(t_{i}\right)\right] \exp \left[\alpha_{\mathrm{Kraf} t} Z_{\mathrm{Kraft}, j}\left(t_{i}\right)\left(t_{i}+t^{c}\right)\right]}\right]^{d_{\mathrm{Kraft}, i}} .
\end{aligned}
$$

At any point in time, the risk set for a specific event (i.e. buying, respectively, Eta or Kraft) consists of those households who have not yet bought that brand. The risk-set composition is thus brand specific, which corresponds to a stratified proportional Cox model. Moreover, we allow for different covariate effects for the two considered events.

The potential dependence between a particular household's two purchase decisions is accounted for in two ways. First, both the post-crisis volume purchased of Kraft (Eta) and the advertising support given to Kraft (Eta) are included in a time-varying way in $X_{\mathrm{Eta}}(t)\left(X_{\mathrm{Kraft}}(t)\right)$. To control for any unobserved correlation between the two hazard rates left, the robust, "clustered" approach advocated in Lin (1994) is adopted to estimate the variance-covariance matrix. This approach accounts for the within-household (i.e. withincluster) correlation in the two timing decisions, while still assuming independence across households (clusters).

\section{References}

Aaker, D. A. (1991). Managing brand equity. New York (NY): Free. Aaker, D. A. (1996). Building strong brands. New York (NY): Free. 
Aaker, D. A., \& Biel, A. L. (1993). Brand equity \& advertising: Advertising's role in building strong brands. Hillsdale, NJ: Erlbaum.

Ahluwalia, R. (2002). How prevalent is the negativity effect in consumer environments? Journal of Consumer Research, 29, 270-279.

Ahluwalia, R., Burnkrant, R. E., \& Rao Unnava, H. (2000). Consumer response to negative publicity: The moderating role of commitment. Journal of Marketing Research, 37, 203-214.

Ahluwalia, R., Burnkrant, R. E., \& Rao Unnava, H. (2001). The moderating role of commitment on the spillover effect of marketing communications. Journal of Marketing Research, 38, 458-470.

Allison, P. D. (1984). Event history analysis: Regressions for longitudinal data. Sage University Paper Series: Quantitative Applications in Social Sciences 07-046.

Berman, B. (1999). Planning for the inevitable product recall. Business Horizons, 42, 69-78.

Bucklin, R. E., Gupta, S., \& Siddarth, S. (1998). Determining segmentation in sales response across consumer purchase behaviors. Journal of Marketing Research, 35, 189-197 (May).

Byzalov, D., \& Shachar, R. (2004). The risk reduction role of advertising. Quantitative Marketing and Economics, 2, 283-320.

Campo, K., Gijsbrechts, E., \& Nisol, P. (2000). Towards understanding consumer response to stock-outs. Journal of Retailing, 76, 219-242.

Cox, D. R. (1972). Regression models and life tables. Journal of the Royal Statistical Society. Series B. 34(2), 187-220.

Davidson, W. N., \& Worrell, D. L. (1992). Research notes and communications: The effect of product recall announcements on shareholder wealth. Strategic Management Journal, 13, 467-473.

Dawar, N. (1998). Product-harm crises and the signaling ability of brands. International Studies of Management and Organization, 28, 109-119.

Dawar, N., \& Pillutla, M. N. (2000). Impact of product-harm crises on brand equity: The moderating role of consumer expectations. Journal of Marketing Research, 37, 215-226.

De Alessi, L., \& Staaf, R. J. (1994). What does reputation really assure? The relationship of trademarks to expectations and legal remedies. Economic Inquiry, 32, 477-485.

Finkelstein, S. (2005). When bad things happen to good companies: Strategy failure and flawed executives. Journal of Business Strategy, 26(2), 19-28.

Gielens, K., \& Dekimpe, M. G. (2007). The entry strategy of retail firms into transition economies. Journal of Marketing, in press.

Goering, P. A. (1985). Effects of product trial on consumer expectations, demand and prices. Journal of Consumer Research, 12, 1-16.

Goldfarb, A. (2006). The medium-term effects of unavailability. Quantitative Marketing and Economics, 4, 143-171.

Hale, J. E., Dulek, R. E., \& Hale, D. P. (2005). Crisis response communication challenges. Journal of Business Communication, $42,112-134$.

Hartley, R. F. (1995). Marketing mistakes (6th ed.). New York (NY): Wiley.

Helsen, K., \& Schmittlein, D. (1993). Analyzing duration times in marketing: Evidence for the effectiveness of hazard rate models. Marketing Science, 12, 395-414.

Herr, P. M., Kardes, F. R., \& Kim, J. (1991). Effects of word-of-mouth and product-attribute information on persuasion: An accessibilitydiagnosticity perspective. Journal of Consumer Research, 17, 454-462.

Hoeffler, S., \& Keller, K. L. (2003). The marketing advantages of strong brands. Brand Management, 10, 421-445.

Jolly, D. W., \& Mowen, J. C. (1985). Product recall communications: The effects of source, media, and social responsibility information. Advances in Consumer Research, 12(1), 471-475.
Kamakura, W. A., \& Russell, G. J. (1989). A probabilistic choice model for market segmentation and elasticity structure. Journal of Marketing Research, 26, 379-390.

Laroche, M., Kim, C., \& Zhou, L. (1996). Brand familiarity and confidence as determinants of purchase intention: An empirical test in a multiple brand context. Journal of Business Research, 37(2), 115-120.

Laufer, D., Gillespie, K., McBride, B., \& Gonzalez, S. (2005). The role of severity in consumer attributions of blame: Defensive attributions in product-harm crises in Mexico. Journal of International Consumer Marketing, 17(2/3), 33-50.

Leeflang, P. S. H., Wittink, D. R., Wedel, M., \& Naert, P. A. (2000). Building models for marketing decisions. Boston: Kluwer.

Lim, J., Currim, I. C., \& Andrews, R. L. (2005). Consumer heterogeneity in the longer-term effects of price promotions. International Journal of Research in Marketing, 22, 441-457.

Lin, D. Y. (1994). Cox regression analysis of multivariate failure time data: The marginal approach. Statistics in Medicine, 13(21), 2233-2247.

Lodish, L. M., Abraham, M., Kalmenson, S., Livelsberger, J., Lubetkin, B., Richardson, B., et al. (1995). How T.V. advertising works: A meta-analysis of 389 real world split cable T.V. advertising experiments. Journal of Marketing Research, 32, 125-139.

Longpre, M., \& Nolan, H. (2007). ConAgra bolsters comms amid peanut butter recall. PRWeek USA, February 23.

Mehta, N., Rajiv, S., \& Srinivasan, K. (2004). Role of forgetting in memory-based choice decisions: A structural model. Quantitative Marketing and Economics, 2, 107-140.

Mitra, D., \& Golder, P. N. (2002). Whose culture matters? Nearmarket knowledge and its impact on foreign market entry timing. Journal of Marketing Research, 39, 350-365.

Mowen, J. C. (1980). Further information on consumer perceptions of product recalls. Advances in Consumer Research, 7(1), 519-523.

Pennings, J. M. E., Wansink, B., \& Meulenberg, M. T. G. (2002). A note on modeling the consumer reactions to a crisis: The case of the mad cow disease. International Journal of Research in Marketing, 19, 91-100.

Rhee, M., \& Haunschild, P. R. (2006). The liability of a good reputation: A study of product recalls in the U.S. automobile industry. Organization Science, 17, 101-117.

Shimp, T. A., Hyatt, E. M., \& Snyder, D. J. (1991). A critical appraisal of demand artifacts in consumer research. Journal of Consumer Research, 18, 273-283.

Stockmeyer, J. (1996). Brand in crisis: Consumer help for deserving victims. Advances in Consumer Research, 23(1), 429-435.

Sydney Morning Herald (1996a). Kraft Ad campaign to cost more than peanuts. November 26.

Sydney Morning Herald (1996b). Peanut butter king loses a kingdom. September 1.

Tellis, G. J., \& Weiss, D. L. (1995). Does TV advertising really affect sales? The role of measures, models, and data aggregation. Journal of Advertising, 24, 1-12.

U.S. Consumer Product Safety Commission (2005). 2005 performance and accountability report.

van Heerde, H. J., Helsen, K., \& Dekimpe, M. G. (2007). The impact of a product-harm crisis on marketing effectiveness. Marketing Science, in press.

Weinberger, M. G., \& Lepkowska-White, E. (2000). The influence of negative information on purchase behavior. Journal of Marketing Management, 16, 465-482.

Winer, R. S. (1999). Experimentation in the 21st century: The importance of external validity. Journal of the Academy of Marketing Science, 27, 349-358. 